Methods A mixed-methods approach was used, incorporating program observation and key informant perspectives. Program data (collected April 2012 to June 2014) and de-identified licensing data from the NT Motor Vehicle Registry were analysed for trends in service delivery and licensing rates pre and postprogram.

Results Stakeholders reported that the program is meeting the needs of underserviced remote communities, and regarded the program as highly engaging and acceptable. There was a greater increase in new licences at intervention sites (Learner 24\% and Open licence 18\%) compared with other remote areas (Learner licence $13 \%$ and Open licence $8 \%$ ). There appeared to be a dose response relationship with greater licence outcomes at communities that received higher levels of program delivery.

Conclusions DriveSafe NT Remote is a Government delivered program that is acceptable to Aboriginal clients in remote NT communities, and is increasing driver licensing rates in these settings. The flexible delivery and culturally responsive approach should allow continuation of positive licensing outcomes.

\section{DOES AN ON-ROAD MOTORCYCLE COACHING PROGRAM REDUCE CRASHES IN NOVICE RIDERS? A RANDOMISED CONTROL TRIAL}

${ }^{1}$ Rebecca Q Ivers, ${ }^{1}$ Chika Sakashita, ${ }^{2}$ Teresa Senserrick, 1,3Jane Elkington, 'Serigne Lo, ${ }^{2}$ Soufiane Boufous, ${ }^{1,4}$ Liz de Rome. ${ }^{1}$ The George Institute for Global Health, University of Sydney, Australia; ${ }^{2}$ Transport and Road Safety Research, the University of NSW, Australia; ${ }^{3}$ New York University, Sydney, Australia; ${ }^{4}$ Neuroscience Research Australia

\subsection{6/injuryprev-2016-042156.521}

Background There is community demand for investment in motorcycle rider training programs but little evidence of its effectiveness in preventing crashes. This randomised trial of an onroad rider coaching program commissioned by VicRoads, the road authority for the State of Victoria, Australia, aimed to determine its effectiveness in reducing crashes in novice motorcycle riders.

Methods Between May 2010 and October 20122399 newlylicensed provisional riders were recruited in Victoria, Australia and completed a telephone interview before randomisation to intervention or control groups. Riders in the intervention group were offered an on-road motorcycle rider coaching program which involved pre-program activities, 4 hours riding and facilitated discussion in small groups with a riding coach. Outcome measures were collected for all participants via telephone interviews at 3 and 12 months after program delivery (or equivalent for controls), and via linkage to police-recorded crash and offence data. The primary outcome was a composite measure of police-recorded and self-reported crashes; secondary outcomes included traffic offences, near crashes, riding exposure, and riding behaviours and motivations.

Results Follow-up was $89 \%$ at 3 months and $88 \%$ at 12 months; $60 \%$ of the intervention group completed the program. Intention-to-treat analyses conducted in 2014 indicated no effect on crash risk at 3 months (adjusted OR 0.90, 95\% CI: 0.65-1.27) or 12 months (adjusted OR 1.00, 95\% CI: 0.78-1.29). Riders in the intervention group reported increased riding exposure, speeding behaviours and rider confidence.

Conclusions There was no evidence that this on-road motorcycle rider coaching program reduced the risk of crash, and we found an increase in crash-related risk factors. Given the absence of road safety benefits such programs should be considered a less promising strategy than other aspects of a safe system approach.

\section{EFFECTIVENESS OF MATERNITY DEPARTMENT INTERVENTION TO IMPROVE SAFETY KNOWLEDGE AND BEHAVIOUR OF CHILD PASSENGER}

${ }^{1}$ Xiangxiang Liu, ${ }^{2}$ Jingzhen Yang, ${ }^{3}$ Liping Li. ${ }^{1}$ Injury Prevention Research Centre, Medical College of Shantou University, China; ${ }^{2}$ The Research Institute at Nationwide Children's Hospital, USA; ${ }^{3}$ Injury Prevention Research Centre, Medical College of Shantou University, China

\subsection{6/injuryprev-2016-042156.522}

Background To test the effectiveness of maternity department intervention to improve knowledge of child passenger safety among newborn parents.

Methods A prospective experimental study which included three groups (one behaviour intervention group, one education intervention group and one control group) was conducted in the maternity department of two hospitals. Both intervention groups received a folded pamphlet of child passenger safety, a height chart and a standardised safety education during their hospital stay after giving birth. The behaviour intervention group received an additional free child car seat (CSS) and professional installation training at discharge. The control group received a pamphlet with no information on child passenger safety, a height chart or an education about infant care. Three months later, a phone interview was conducted among the participants in the three groups. Data on the child passenger safety knowledge, attitudes, and use of CSS were collected and evaluated before and after the intervention.

Results No significant difference observed in demographics among the three groups. There was a significant difference in CSS use among the three groups before and after the intervention $\left(\chi^{2}=19.6109, \mathrm{P}=0.0001\right)$. In the behaviour intervention group, the knowledge of safety belt $\left(\chi^{2}=13.1680, \mathrm{P}=0.0003\right)$, safety airbag $\left(\chi^{2}=51.0545, \mathrm{P}=0.0000\right)$, and CSS legislation $\left(\chi^{2}=10.0838, \mathrm{P}=0.0015\right)$ increased statistically after the intervention; and the drivers wearing safety belt increased from $90 \%$ to $100 \%\left(\chi^{2}=5.2525, \mathrm{P}=0.0219\right)$; answering phone without device reduced from $29 \%$ to $4 \%\left(\chi^{2}=11.8837, \mathrm{P}=0.0006\right)$. In the education group, the knowledge of safety airbag $\left(\chi^{2}\right.$ $=5.8667, \mathrm{P}=0.0154)$, and CSS $\left(\chi^{2}=5.4363, \mathrm{P}=0.0197\right)$ increased statistically after the intervention; and the drivers wearing safety belt increased from $66 \%$ to $86 \%\left(\chi^{2}=5.0661\right.$, $\mathrm{P}=0.0244)$. In the control group, except the statistically significant increase on the knowledge of CSS $\left(\chi^{2}=4.4308\right.$, $\mathrm{P}=0.0353$ ), there was no statistically changes in other study measures; and the drivers wearing safety belt increased from $75 \%$ to $95 \%\left(\chi^{2}=6.400, \mathrm{P}=0.0114\right)$.

Conclusion Lack of knowledge and poor perception contributed to low use of CSS. Interventions that combine a free CSS with child passenger safety education were effective in improving newborn parents' knowledge and use of CSS. The results of this study will be useful in development of effective interventions promoting child passenger safety.

\section{TRAFFIC-RELATED INJURIES AMONG THE YOUTH IN THE UNITED ARAB EMIRATES: A PROSPECTIVE TRAUMA REGISTRY-BASED STUDY}

${ }^{1}$ Michal Grivna, ${ }^{2}$ Hani $O$ Eid, ${ }^{2}$ Fikri M Abu-Zidan. ${ }^{1}$ Institute of Public Health, College of Medicine and Health Sciences, UAE University, Al Ain, UAE; ${ }^{2}$ Department of Surgery, College of Medicine and Health Sciences, UAE University, Al Ain, UAE

10.1136/injuryprev-2016-042156.523 
Background Traffic-related injuries are the largest cause of premature morbidity and leading cause of death among the youth in the UAE. Those injuries are relatively neglected. Our aim was to study epidemiology, risk factors and outcome of hospitalised injured patients 15-24 years in order to give recommendations for prevention.

Methods We prospectively studied all youth patients with trafficrelated injuries admitted to $\mathrm{Al}$ Ain or Tawam Hospitals, Al-Ain City, or who died after arrival to the hospital, during an 18 months period. Demography, location and time of injury, other body region, severity, hospital and intensive care unit (ICU) stay were analysed.

Results 333 patients having a mean age of 20 years (SD 2.5) were studied. $87.1 \%$ were males and $71.5 \%$ were UAE nationals. The most common location for injury was highway and street $(82.8 \%)$ followed by off-road (7.2\%). Majority of injured patients $(69.6 \%)$ were drivers or front-seat passengers, followed by back seat passengers (15.6\%), motorcyclists $(8.7 \%)$ and pedestrians (4.5\%). Rollover was most often crash mechanism (29.7\%), followed by front crash $(29.4 \%)$ and side-angle (16.2\%). 15\% of patients were ejected from the car during rollover crash. Evening (18-24) was the most common time of the day $(33.5 \%)$ and Sunday the most common day of the week (20.1\%) when crash occured. $19.8 \%$ of the patients were admitted to the ICU. Median Glasgow Coma Scale was 15 (Range 315), Injury Severity Score 5 (1-41), Revised Trauma Score 12 (712) and median total hospital stay was 3 (Range 1-73). 9 (2.7\%) patients died.

Conclusions Young UAE-national males are at a higher risk of being injured at traffic. Rollover crash was frequent with high risk of ejection. Promotion of traffic safety and enforcement of safety legislation is neccesary.

\section{PREVENTING MOTOR VEHICLE-RELATED FATALITIES: A COLLABORATIVE PROJECT TO ENHANCE CORONIAL DATA CAPTURE AND USE}

${ }^{1,2,3}$ Sarah A Richmond, ${ }^{1}$ Devon Williams, ${ }^{4}$ Ian Pike, ${ }^{5}$ Dirk Huyer, ${ }^{6}$ Lisa Lapointe, ${ }^{1,7}$ Colin Macarthur, ${ }^{1,7}$ Andrew Howard. ${ }^{1}$ Hospital for Sick Children, Canada; ${ }^{2}$ York University, Canada; ${ }^{3}$ University of Calgar, Canada; ${ }^{4}$ University of British Columbia, Canada; ${ }^{5}$ Ministry of Community Safety and Correctional Services, Ontario Canada; ${ }^{6}$ Ministry of Justice, British Columbia, Canada; ${ }^{7}$ University of Toronto, Canada

\subsection{6/injuryprev-2016-042156.524}

Background Child fatalities due to motor vehicle collisions (MVCs) are a significant burden in Canada. Data specific to these deaths are often referenced, yet few Canadian jurisdictions systematically collect comprehensive details of all child occupant and pedestrian MV fatalities reducing the effectiveness of informing and setting targets for injury prevention initiatives.

Methods This project had two objectives; 1): To document the details of injuries and specific crash circumstances of all fatally injured child and youth (0-18 years) occupants and pedestrians through review of two provincial coroner case files (2004-2012). 2): To introduce recommendations toward standardised data collection procedures for use by coroners, specific to child and youth occupants and pedestrians involved in fatal MVC to: a) support revision of procedures, processes, and practices to facilitate detailed data capture by coroners; and b) to improve information transfer to inform prevention initiatives.
Results Phase 1: Review of death investigation files $(\mathrm{n}=317)$ did not allow ascertainment of suitable detail about injuries $(56.5 \%, \mathrm{n}=160)$, restraint status $(38.1 \%, \mathrm{n}=121)$ and crash type $(7.3 \%, \mathrm{n}=23)$. Data obtained in the retrospective review revealed $43 \%$ (95\% CI: 36.3, 50.0) of cases were side impact collisions, and $40.0 \%$ (95\% CI: $33.0,48.0)$ of the fatalities were reported improperly or unrestrained. Phase 2: A standardised form was developed and provided to each provincial coroner service to facilitate consistent and detailed data collection. Prospective data collection reduced missing data to $0 \%$.

Conclusions Review of data obtained from review of child and youth fatalities demonstrated a significant proportion of deaths followed side impact collisions without use of restraint systems; however, detailed information about MVC circumstances and injury details were not present in the investigation files. Stakeholder involvement plays a pivotal role in attaining data that are imperative to the development of effective injury prevention products, policies and practices.

\section{YOUNG DRIVER CRASHES - THE INFLUENCE OF ROAD SINUOSITY}

${ }^{1}$ Sarah J Jones, ${ }^{2}$ Ronan A Lyons. ${ }^{1}$ Public Health Wales; ${ }^{2}$ Swansea University

\subsection{6/injuryprev-2016-042156.525}

Background Young drivers (YD) are at high risk of crashing because of their age and inexperience, leading some to 'test' themselves on roads that they perceive to be more challenging. While this may have applied more to male YD in the past, crash data indicate that whilst male YD crashes have decreased rapidly in recent years, female YD crashes have decreased much more slowly. Research suggests that female YD are beginning to show behaviours previously seen as 'male' and linked to crash risk. This paper aimed to examine the links between road crashes amongst male and female YD and older drivers (OD) and road sinuosity.

Methods Police road crash data on single vehicle crashes were analysed for Wales for 2000-2013. Young drivers were aged 1719 years and older drivers aged 30-59 years. Each crash was linked to the road network segment (length of road between two consecutive junctions) on which it occurred. Sinuosity of the segment was the ratio of the actual segment length to the straight line distance between start and end of the segment. Analysis was by year, for males and females and for night-time $\mathrm{v}$ day time.

Results For 17-19 year male YD, 95 ${ }^{\text {th }}$ percentile sinuosity values ranged from 1.14 to 1.24 , with no trends. For females aged 17$19,95^{\text {th }}$ percentile values ranged from 1.12 to 1.36 and showed a trend to increasing sinuosity of road crash segments. Amongst OD $95^{\text {th }}$ percentile sinuosity values were lower (1.11-1.28 for males, 1.12-1.31 for females) and decreased over time.

Conclusions YD crashes occur on more sinuous roads than OD crashes. This confirms previous findings around road type and relates specifically to the section of road on which the crash occurred. Realistically though, making the road network less sinuous is not a viable intervention; therefore addressing factors that place YD at higher risk on these roads is important. For YD, this means restricting alcohol consumption, passenger carriage and night-time driving, in short Graduated Driver Licensing. 